EGU2020-3557

https://doi.org/10.5194/egusphere-egu2020-3557

EGU General Assembly 2020

(c) Author(s) 2020. This work is distributed under

the Creative Commons Attribution 4.0 License.

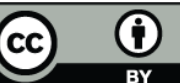

\title{
Remote predictive geological mapping as a tool for the reconstruction of the complex geodynamic evolution of Melanesia
}

\author{
Philipp BrandI ${ }^{1}$, Anna Kraetschell ${ }^{1}$, Justin Emberley ${ }^{2}$, Mark Hannington ${ }^{1,2}$, Margaret Stewart ${ }^{3}$, Sven \\ Petersen ${ }^{1}$, and Alan Baxter ${ }^{2}$ \\ ${ }^{1}$ GEOMAR Helmholtz Centre for Ocean Research Kiel, Marine Mineral Resources, Kiel, Germany (pbrandl@geomar.de) \\ ${ }^{2}$ Department of Earth and Environmental Sciences, University of Ottawa, Canada \\ ${ }^{3}$ Department of Earth and Environmental Sciences, Mount Royal University, Calgary, Canada
}

The offshore regions of Eastern Papua New Guinea and the Solomon Islands include several active and remnant arc and backarc systems that formed in response to complex plate tectonic adjustments following subduction initiation in the Eocene. Although there has been extensive exploration for offshore petroleum resources, and more than 54 research cruises have investigated or transited the region since 1993, a comprehensive regional geological map, including the deep marine areas, has not been available at a scale that permits quantitative analysis of the basin history. We present the first map that depicts interpreted assemblage- and formation-level lithostratigraphic units correlated across the marine basins and adjacent land masses. The mapped assemblages and large-scale formations are based on a compilation of landbased geological maps, marine geophysical data (hydroacoustics, magnetics, and gravity) integrated with the results of geological sampling, ocean drilling, seismic surveys, and seabed observations.

More than $400,000 \mathrm{~km}^{2}$ of the map area covered by ship-based multibeam and other geophysical data were inspected to derive the offshore geological units. In areas with limited data, the units were extrapolated from well-documented formations in adjacent regions with more complete information, including on land. This approach follows closely the techniques used for remote predictive mapping in other regions of the Earth where geological information is sparse. Geological boundaries were constrained by ship-based multibeam data reprocessed at 35-m to 50-m resolution and integrated with the Global Multi-Resolution Topography (GMRT) gridded at $100 \mathrm{~m}$. Lithotectonic assemblages were assigned on the basis of plate structure, crustal type and thickness, age, composition, and sedimentary cover and further refined by bathymetric and geophysical data from the literature and cruise reports. The final compilation is generalized and presented here at 1:1 M. Our new approach integrates conventional mapping on land with remote predictive mapping of the ocean floor.

The newly compiled geological map illustrates the diversity of assemblages in the region and its complex geodynamic evolution. The resolution of our map allows to perform quantitative analyses of area-age relationships and thus crustal growth. Further geoscientific analyses may allow to 
estimate the regional mineral potential and to delineate permissive areas as future exploration targets. 